\title{
Molecular modeling studies, synthesis, configurational stability and biological activity of 8-chloro-2,3,5,6-tetrahydro-3,6-dimethyl-pyrrolo [1,2,3-de]-1,2,4-benzothiadiazine 1,1-dioxide
}

\author{
Umberto M. Battisti $^{\text {a }}$, Marina M. Carrozzo ${ }^{\mathrm{b}}$, Giuseppe Cannazza ${ }^{\mathrm{a}, *}$, Giulia Puia ${ }^{\mathrm{c}}$, Luigino Troisi $^{\mathrm{b}}$, \\ Daniela Braghiroli ${ }^{\mathrm{a}}$, Carlo Parenti ${ }^{\mathrm{a}}$, Krzysztof Jozwiak $^{\mathrm{d}}$ \\ a Dipartimento di Scienze Farmaceutiche, Università degli Studi di Modena e Reggio Emilia, Via Campi 183, 4100 Modena, Italy \\ ${ }^{\mathrm{b}}$ Dipartimento di Scienze e Tecnologie Biologiche ed Ambientali, Università del Salento, Via Prov.le Lecce-Monteroni, 73100 Lecce, Italy \\ ${ }^{\mathrm{C}}$ Dipartimento di Scienze Biomediche, Università degli Studi di Modena e Reggio Emilia, Via Campi 183, 41100 Modena, Italy \\ ${ }^{\mathrm{d}}$ Laboratory of Medicinal Chemistry and Neuroengineering, Department of Chemistry, Medical University of Lublin, ul.W.Chodzki 4a, 20-093 Lublin, Poland
}

\section{A R T I C L E I N F O}

\section{Article history:}

Received 28 June 2011

Revised 28 September 2011

Accepted 30 September 2011

Available online 5 October 2011

\section{Keywords:}

Benzothiadiazines

AMPA receptor

Positive modulators

\begin{abstract}
A B S T R A C T
The potential therapeutic benefit of compounds able to activate AMPA receptors (AMPArs) has led to a search for new AMPAr positive modulators. Among them, 8-chloro-2,3,5,6-tetrahydro-3,6-dimethyl-pyrrolo[1,2,3-de]-1,2,4-benzothiadiazine 1,1-dioxide (1) has attracted particular attention, because it is one of the most active benzothiadiazine-derived positive modulators of the AMPA receptor. It possesses two stereogenic centers, C3 and C6, thus it can exist as four stereoisomers. In this work, preliminary in silico studies suggested that $\mathbf{1}$ interacts stereoselectively with AMPArs. Single stereoisomers of $\mathbf{1}$ were prepared in order to evaluate their biological activity. However, studies regarding the configurational stability of the investigated compounds suggested a rapid epimerization at C3 in aqueous solvents, and we can expect the same reaction in vivo. Thus, electrophysiological experiments were performed on the two epimeric mixtures, $\left(3^{*}, 6 R\right)$ - and $\left(3^{*}, 6 S\right)$ - 8-chloro-2,3,5,6-tetrahydro-3,6-dimethyl-pyrrolo[1,2,3-de]-1,2,4benzothiadiazine 1,1-dioxide, in order to evaluate their activities as positive allosteric modulators of AMPArs. The obtained data suggest that the $\left(3^{*}, 6 S\right)$ epimeric mixture is the most active in positively modulating AMPArs, confirming in silico results.
\end{abstract}

(c) 2011 Elsevier Ltd. All rights reserved.

\section{Introduction}

L-Glutamate is the principal excitatory neurotransmitter in the mammalian central nervous system (CNS), which can activate ionotropic and metabotropic receptors. ${ }^{1-4}$ An excessive excitation of glutamate receptors observed during stroke, ischemia and similar conditions, mainly due to uncontrolled release of glutamate, leads to neuronal degeneration. On the other hand, reduced functionality of such receptors seems to be involved in learning and memory deficits associated with neurodegenerative diseases like Alzheimer's disease and schizophrenia. ${ }^{5}$ Many studies have been carried out to develop compounds able to enhance glutamatergic function without causing excitotoxicity. In this context, there is a rapidly growing interest in positive allosteric modulators of the $\alpha$-amino-3-hydroxy-5-methyl-4-isoxazolpropionic acid receptor (AMPAr) for their therapeutic properties as potentiators of glutamatergic function without the side effects of direct agonists. ${ }^{1-5}$

\footnotetext{
* Corresponding author. Tel.: +39 059 2055136; fax: +39 0592055750.

E-mail address: giuseppe.cannazza@unimore.it (G. Cannazza).
}

Several positive modulators of AMPA receptors have been described in the last two decades. ${ }^{6-14}$ These agents bind to allosteric sites and enhance receptor function by decreasing desensitization and/or deactivation.

Among the different classes of positive allosteric modulators of AMPArs, benzothiadiazines are one of the most investigated, suggesting their potential utility for a variety of clinical indications such as schizophrenia, depression, Alzheimer's disease, Parkinson's disease, ADHD, and respiratory depression. ${ }^{13-21}$

Compound 1 (Fig. 1) has attracted particular attention, since it is one of the most active benzothiadiazine-derived positive modulators of the AMPA receptor. ${ }^{15}$ Compound 1 possesses two stereogenic centers, C3 and C6, thus it can exist as four stereoisomers (Fig. 1). A primary goal of the present work was to evaluate stereoselective interaction of $\mathbf{1}$ with the AMPAr GluA2 subunit using docking studies.

In order to confirm the results obtained by docking studies, single stereoisomers of $\mathbf{1}$ were synthesized and their biological activity was evaluated.

Since it is known that chiral 2,3-dihydrobenzothiadiazines are configurationally labile, it became important to evaluate the 
<smiles>C[C@@H]1CN2c3c1cc(Cl)cc3S(=O)(=O)N[C@H]2C</smiles>

$(3 S, 6 S)-1$<smiles>C[C@@H]1CN2c3c1cc(Cl)cc3S(=O)(=O)N[C@H]2C</smiles>

$(3 S, 6 R)-1$<smiles>C[C@@H]1CN2c3c1cc(Cl)cc3S(=O)(=O)N[C@H]2C</smiles>

$(3 R, 6 S)-1$

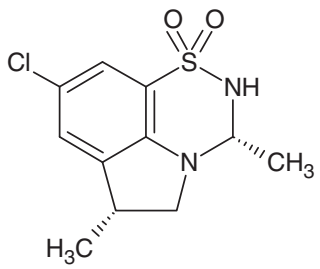

$(3 R, 6 R)-1$
Figure 1. Stereoisomers of 8-chloro-2,3,5,6-tetrahydro-3,6-dimethyl-pyrrolo[1,2,3de]-1,2,4-benzothiadiazine 1,1-dioxide (1).

stability of single stereoisomers of $\mathbf{1}$ in order to obtain reliable pharmacological results. ${ }^{22-28}$

With this aim, the stopped-flow bidimensional recycling HPLC (sf-BD-rHPLC) method, recently developed by our research group, was employed to investigate stereo and chemical stability of $\mathbf{1}$ under conditions similar to those of pharmacological experiments. ${ }^{26,27}$

\section{Results and discussion}

\subsection{Docking studies}

Since previous studies suggested that chiral benzothiadiazines display a stereoselective pharmacological action, it was important to evaluate the activity of single stereoisomers of $\mathbf{1}$ as AMPAr modulators. $^{29,30}$

Taking advantage of crystal structures of the AMPA GluA2 ligand binding domain co-crystallized with several benzothiadiazines, Molegro Virtual Docker (MVD) software was applied to dock 1 with the binding pocket of the GluA2 dimer interface. ${ }^{31,32}$ The software MVD was evaluated on cyclothiazide, IDRA21, trichloromethiazide and hydrochlorothiazide. The average root mean square distance (RMSD) of the best ranked pose of tested compounds compared to their binding pose in their respective crystal structures was found to be $0.66 \AA$ (CTZ $0.41 \AA$; IDRA21 $0.50 \AA$ Á; trichlormethiazide $0.77 \AA$; hydrochlorothiazide $0.97 \AA$ ), proving that MVD is able to accurately dock this class of compounds. ${ }^{31}$ Among the tested crystal structures, the GluA2 dimer in complex with IDRA21 was selected for docking studies of $\mathbf{1}$. Before docking $\mathbf{1}$, a conformational analysis was necessary to identify possible bioactive conformations to use as input structures. As reported by Harpsoe et al. the flexibility of 1 resides only in the sulfonamidic ring. ${ }^{29}$ Since two ring conformations are possible and the hydrogen atom on $\mathrm{N} 2$ can be located in an axial or equatorial position, there are four possible conformers for each stereoisomer of $\mathbf{1}$. The global energy minimum conformer was previously calculated to have the $\mathrm{N} 2$ hydrogen in an axial position and the methyl substituent at C3 in an equatorial position. ${ }^{29}$ IDRA2 1 displays an analogous conformation in the crystal structure in complex with the GluA2 dimer (PDB code 3IL1) confirming that the conformer with an N2 axial hydrogen and a C3 equatorial methyl could be employed for further docking studies. ${ }^{31}$ The docking protocol template was built using the following chemical properties of

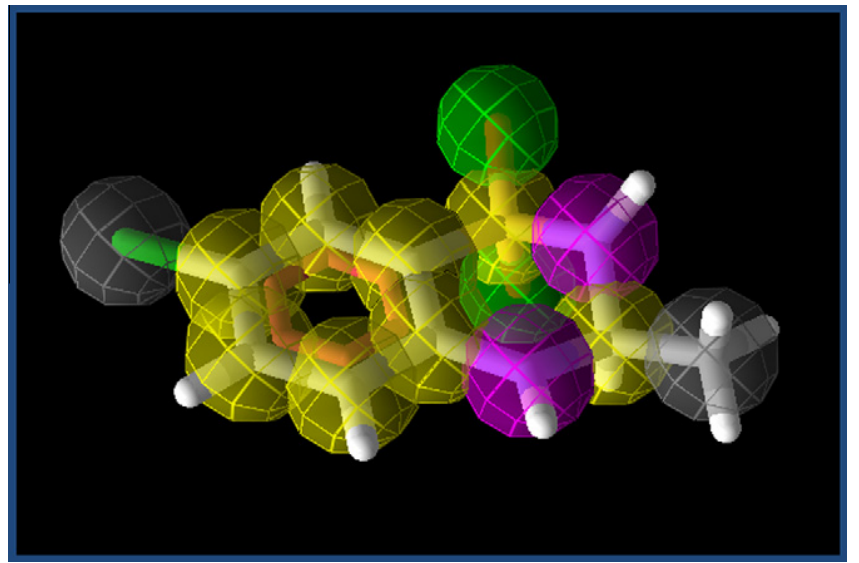

Figure 2. MVD docking template (IDRA21). Yellow: ring atoms; green: hydrogenbond acceptors; purple: hydrogen-bond donors, gray: steric.

IDRA21: ring atoms, hydrogen-bond acceptors, hydrogen-bond donors, and steric interactions (Fig. 2). The docking output clearly indicated a common orientation of the benzothiadiazine core in the ligand binding site for each stereoisomer of $\mathbf{1}$ (Fig. 3 ).

The principal interactions were between $\mathrm{N} 4$ and a sulfone oxygen of the benzothiadiazine with S754 and G731 of the GluA2 domain, respectively. ${ }^{31}$ These interactions were observed for all stereoisomers of $\mathbf{1}$ in the best ranked poses. Furthermore MVD software predicted the highest affinity stereoisomer to be (3S,6S)-1 (Table 1).

The $S$ configuration of the $C 3$ atom imposes an axial orientation on the N2 hydrogen, allowing a polar interaction between the ligand and P494 (Fig. 4). An analogous interaction was observed in the S1S2 GluA2 crystal structure in complex with IDRA21, suggesting that this interaction is probably responsible for the higher affinity of the $3 S$ diastereomers of $\mathbf{1}$ compared to their $3 R$ analogs. The distance between the N2 hydrogen of $(3 S, 6 S)-1$ and the carbonyl oxygen of P494 is $2.81 \AA$ (Fig. 4); when the configuration of $\mathrm{C} 3$ is reversed in $(3 R, 6 S)-\mathbf{1}$ the bond distance increases to $5.23 \AA$ (Fig. 4). Moreover the $S$ configuration of the $C 6$ atom permits the methyl group on $\mathrm{C} 3$ to point directly to the lipophilic cleft formed by the backbone of P494, F495 and M496 (Fig. 3C). ${ }^{29}$

Furthermore $(3 S, 6 R)-\mathbf{1}$ shows a lower affinity value respect to (3S,6S)-1, probably due to the steric hindrance between a C6 methyl group in an $R$ configuration and S729 (Fig. 5). ${ }^{29,31}$ Docking output poses indicate a dramatic decrease in affinity for $(3 R, 6 S)-\mathbf{1}$ compared to $(3 S, 6 S)-\mathbf{1}$, due to the lack of a polar interaction between the N2 hydrogen and P494 (Fig. 3B). (3R,6R)-1 is the least active stereoisomer due to steric interaction between the C6 methyl group and S729 and the absence of polar interaction between the N2 hydrogen and P494 (Fig. 3D).

\subsection{Synthetic procedures}

The mixture of all four stereoisomers of $\mathbf{1}$ was synthesized as previously reported by Philips et al. ${ }^{15}$ In a first effort to obtain single stereoisomers of $\mathbf{1}$, the mixture was tentatively separated on different commercially available chiral stationary phases (CSPs) (OJ, OB, OD). Unfortunately, no baseline resolution was observed for any of the chromatographic conditions tested. Hence, the two epimeric mixtures of 1 were obtained following a synthetic/chromatographic strategy similar to that previously developed for a compound structurally related to $\mathbf{1}$ (Scheme 1 ). ${ }^{26}$ Briefly, single enantiomers of 2,3dihydro-3-methyl- $1 \mathrm{H}$-indole (3) were obtained by derivatization of racemic 3 with di-tert-butyl dicarbonate $\left(\mathrm{BOC}_{2} \mathrm{O}\right)$ to afford 4 . Enantioresolution of $\mathbf{4}$ by chiral chromatography on a semipreparative 
A

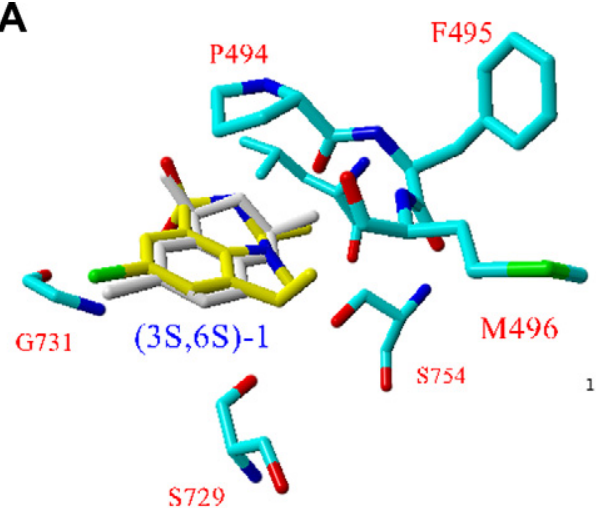

C

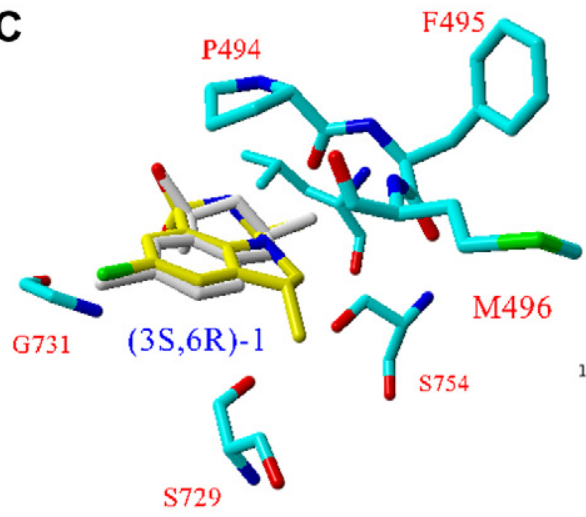

B
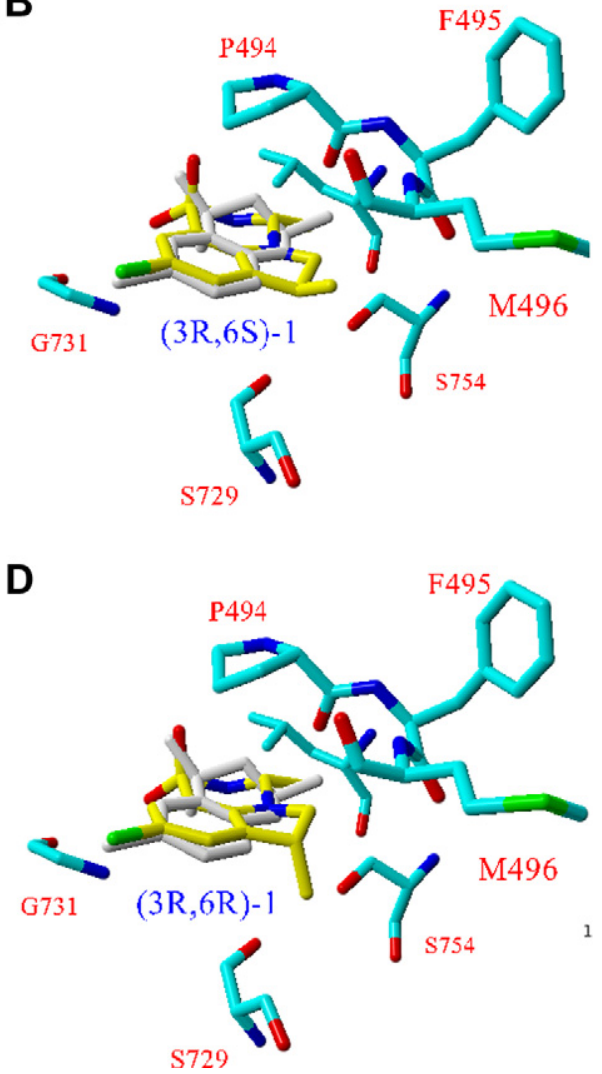

Figure 3. Binding mode of (3S,6S)-1 (A), (3R,6S)-1 (B), (3S,6R)-1 (C), (3R,6R)-1 (D) and IDRA21(gray) in S1S2J GluA2.

Table 1

Docking results for the four stereoisomers of $\mathbf{1}$

\begin{tabular}{lll}
\hline Stereoisomer of $\mathbf{1}$ & Moldock & Rerank \\
\hline $3 S, 6 S$ & -106.8 & -86.9 \\
$3 R, 6 S$ & -101.1 & -81.5 \\
$3 R, 6 R$ & -96.7 & -74.0 \\
$3 S, 6 R$ & -104.3 & -84.2
\end{tabular}

$\overline{(3 S, 6 S)-\mathbf{1} \text { Isomer possesses the lowest scoring, while the }(3 R, 6 R)-\mathbf{1} \text { isomer possesses }}$ the highest scoring (lowest binding). These data suggest that the $S$ configuration is preferred over the $R$ at both chiral centers.

Chiralcel OD column was achieved with baseline separation. Single enantiomers were then deprotected, and absolute configurations of single enantiomers of $\mathbf{3}$ were assigned by comparing optical rotation data with those reported in literature. ${ }^{26,33}(S)$ - and $(R)-$
2,3-dihydro-3-methyl-1H-indole ( $S$-3 and $R$-3) enantiomers were employed to prepare $(S)$ - and $(R)-2,3$-dihydro-3-methyl-1H-indol7 -sulfonamide ( $S-\mathbf{5}$ and $R-\mathbf{5}$ ). Subsequently the epimeric mixtures $\left(3^{*}, 6 R\right)-6$ and $\left(3^{*}, 6 S\right)-6$ were obtained by ring closure of $(R)-2,3-$ dihydro-3-methyl-1H-indol-7-sulfonamide $(R-5)$ and $(S)-2,3$-dihydro-3-methyl-1H-indol-7-sulfonamide $(S-5)$ with acetaldehyde. $\left(3^{*}, 6 R\right)-6$ and $\left(3^{*}, 6 S\right)-6$ were chlorinated with $N$-chlorosuccinimide in order to obtain the epimeric mixtures $\left(3^{*}, 6 R\right)-\mathbf{1}$ and $\left(3^{*}, 6 S\right)-\mathbf{1}$ (See Section 4).

The two epimeric mixtures of $\mathbf{1}$ were subsequently resolved by chromatography employing a Chiralcel OD column under both normal and reverse phase conditions. A baseline separation was obtained for $\left(3^{*}, 6 R\right)-\mathbf{1}$ epimers while a partial separation was achieved for $\left(3^{*}, 6 S\right)-\mathbf{1}$ epimers.

In order to isolate the single epimers of $\left(3^{*}, 6 R\right)-\mathbf{1}$, the analytical method was scaled to a semipreparative level. By employing a
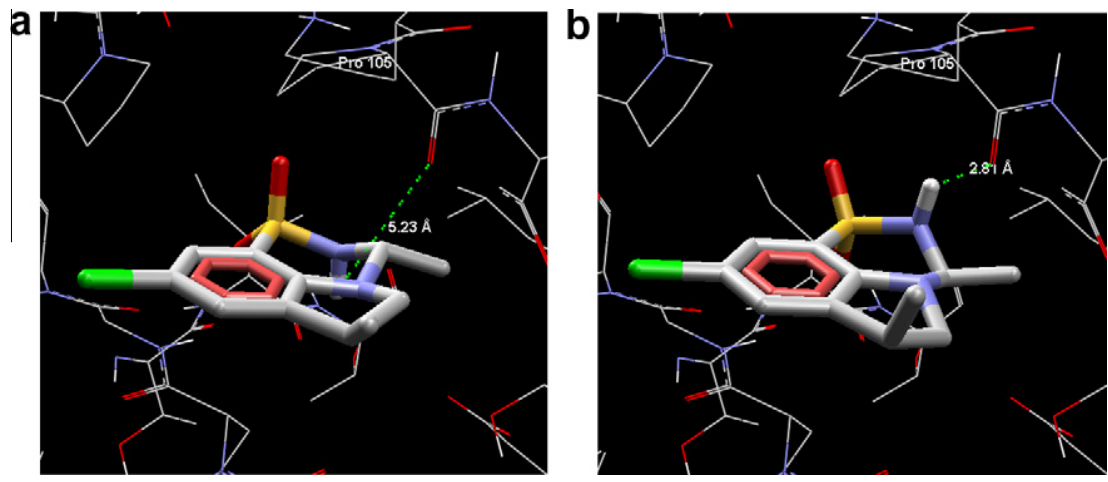

Figure 4. Binding mode of (3R,6S)-1 (a) and (3S,6S)-1 (b). 

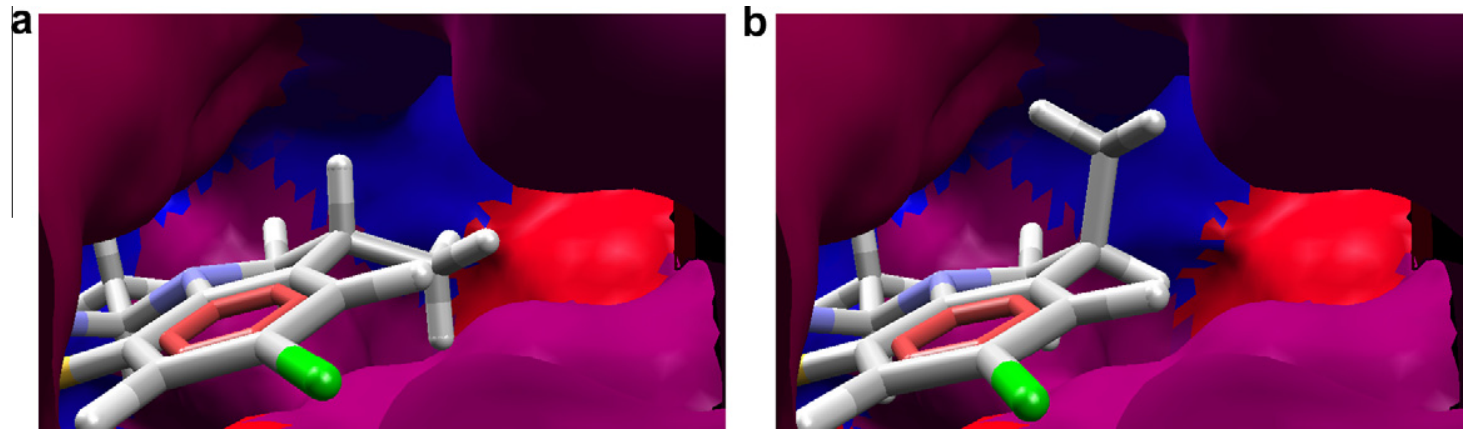

Figure 5. Docking of (3S,6R)-1 (a) and (3S,6S)-1 (b) at the GluA2 dimer interface (hydrophobic residues are in blue, hydrophilic residues are in red).

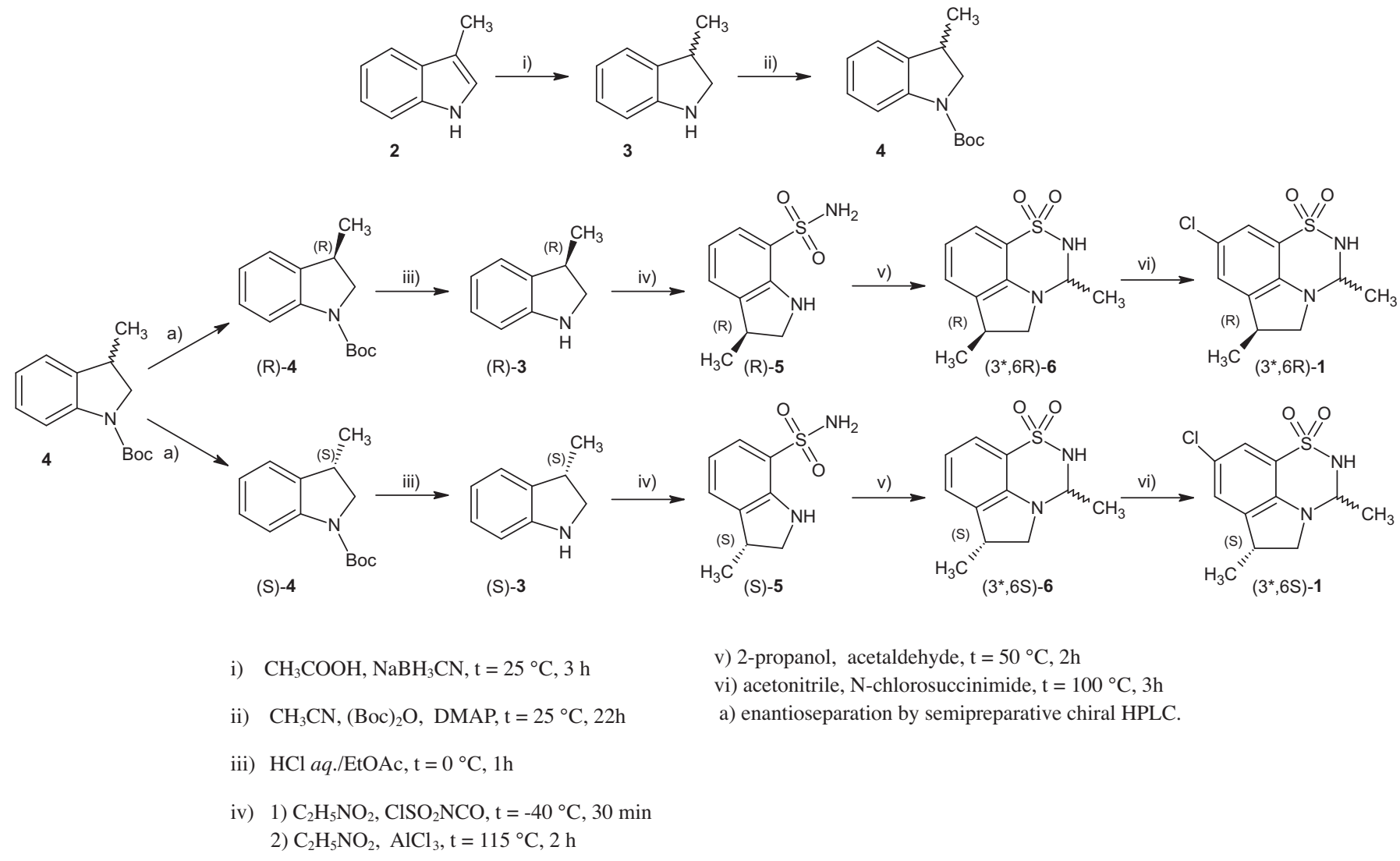

Scheme 1. Synthetic/chromatographic preparation of epimeric mixtures of $\mathbf{1}$.

semipreparative Chiralcel OD column and hexane/2-propanol $70: 30(\mathrm{v} / \mathrm{v})$ as a mobile phase, fractions corresponding to single epimers of 1 were harvested.

The epimeric composition of each fraction was determined prior to and after evaporation of mobile phase (70:30 v/v hexane/2-propano) under reduced pressure. Single pure stereoisomers were present prior to evaporation of mobile phase, while the epimeric mixture was detected after evaporation of solvents. These results indicate that single stereoisomers of $\mathbf{1}$ undergo a rapid epimerization process during evaporation of mobile phase, suggesting that the chiral C3 atom of $\mathbf{1}$ is configurationally unstable.

Hence, before performing studies of biological activity on single stereoisomers of $\mathbf{1}$, it was important to evaluate their configurational stability in order to obtain reliable pharmacological results.

\subsection{Configurational and chemical stability of 8-chloro-2,3,5,6- tetrahydro-3,6-dimethyl-pyrrolo[1,2,3-de]-1,2,4- benzothiadiazine, 1,1-dioxide (1)}

Preliminary investigations concerning configurational stability of epimeric mixture $\left(3^{*}, 6 R\right)$-1 were performed by dynamic chromatography (DHPLC). When $\left(3^{*}, 6 R\right)-\mathbf{1}$ was chromatographed on a Chiralcel OD column at temperatures above $25^{\circ} \mathrm{C}$ employing water/acetonitrile as a mobile phase, an epimeric plateau was observed between the two peaks. No epimerization occurred during separation on a Chiralcel OD column using non aqueous solvents as mobile phase (hexane/2-propanol). These data are in accordance with our previous studies that indicated a rapid enantiomerization in aqueous solvents at chiral carbon C3 of 2,3-dihydrobenzothiadiazine type compounds structurally related to $\mathbf{1}^{22-28}$ (Scheme 2). 


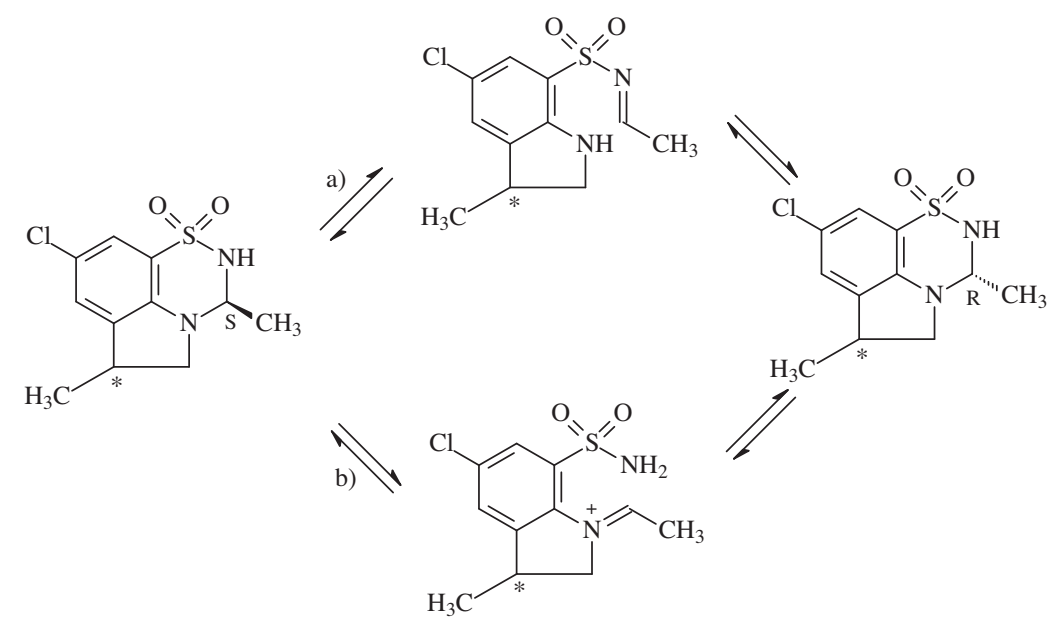

Scheme 2. Proposed epimerization mechanism. (a) Neutral/basic conditions (b) acidic conditions.

Employing DCXplorer software developed by Trapp, it was possible to calculate epimerization rate constants by integration of the area of the interconverting peaks. ${ }^{34-43}$

The analysis of $\left(3^{*}, 6 R\right)-\mathbf{1}$ was performed at different temperatures between 5 and $37{ }^{\circ} \mathrm{C}$ using a Chiralcel OD-R column and 50:50 (v/v) water/acetonitrile as mobile phase. The rate constants and free energy barriers of epimerization calculated with DCXplorer are reported in Table 2. The data obtained indicated that the epimerization rate increases with increases in temperature. Dynamic chromatographic methods, however, constrained calculation of epimerization kinetic constants of $\left(3^{*}, 6 R\right)-1$ in the presence of chiral stationary phase (CSP) and mobile phase, which could influence reaction rates. Therefore kinetic parameters of epimerization obtained by dynamic chromatography can be different from those obtained when stereoisomers are dissolved in biological fluids and are in contact with cellular membranes.

Recently we developed a stopped-flow bidimensional recycling HPLC (sf-BD-rHPLC) method that permits the evaluation of configurational and chemical stability of pharmaceutical compounds under conditions similar to those in vivo. ${ }^{26,27}$ The method offers several advantages with respect to methods reported in literature. In particular it allows the calculation of epimerization rate constants on the epimeric mixture directly without the necessity of having single epimers like the classical batch-wise method. It is possible to conduct epimerization in solvents similar to physiological fluids and not in mobile phase that contains an organic modifier that could influence rate of interconversion like in dynamic and stopped-flow methods. Moreover, the sf-BD-rHPLC method permits one to choose the appropriate stationary phase in which epimerization will be conducted; in this manner it is possible to avoid stereospecific interactions that could stabilize one stereoisomer over another thus influencing epimerization rates.

Since epimers are contact with biological membranes and dissolved in physiological solutions in biological activity experiments, configurational stability can be evaluated under the same conditions in order to obtain reliable biological activity data for single stereoisomers of $\mathbf{1}$.

Recently stationary phases that simulate biological membranes were employed in the evaluation of solute/membrane partition coefficients of pharmaceutical compounds. ${ }^{44-46}$ In particular C8 and C18 stationary phases were extensively employed to evaluate partition coefficients giving good correlation with $\log P$ obtained with the classical octanol/water distribution method. More recently, an immobilized artificial membrane (IAM) stationary phase composed of lecithin monolayers (phosphatidylcholine), wherein each lipid molecule is covalently linked to propylamine/silica, became commercially available, enabling the accurate calculation of solute/membrane partition coefficients. ${ }^{46-49}$

Hence, by using C8 or IAM stationary phases as reactor columns in the sf-BD-rHPLC method it was possible to evaluate the configurational stability of $\left(3^{*}, 6 R\right)-\mathbf{1}$ under experimental conditions that resemble those of the stomach $(\mathrm{pH} 2.2)$ and plasma $(\mathrm{pH} \mathrm{7.0)}$ at $37.5^{\circ} \mathrm{C}$.

The data obtained with the sf-BD-rHPLC method, reported in Tables 3 and 4, indicated that epimerization occurs with similar kinetics on both $\mathrm{C} 8$ and IAM columns with half-times in the range of 10-20 min. Moreover, $\mathrm{pH}$ slightly influenced the rate constants of epimerization, since only small differences were observed at the two pH's tested. These data suggest that the in vivo administration of single stereoisomers of $\mathbf{1}$ lacks significance since it could undergo epimerization before reaching the target receptor in the brain.

Surprisingly compound $\mathbf{1}$ was stable to hydrolysis under acidic conditions, since no hydrolysis occurred at $\mathrm{pH} 2.2$ at $37.5^{\circ} \mathrm{C}$ for at least $90 \mathrm{~min}$.

Previous studies on the chemical stability of benzothiadiazines structurally related to 1 , like IDRA21, indicated their rapid hydrolysis in acidic solvents. ${ }^{22-28}$ Further studies have suggested that IDRA21, when orally administered, hydrolyzes in 2-amino-5-chlorobenzensulfonamide, which was detected at high levels in rat brain together with single enantiomers of IDRA21 itself. ${ }^{50}$ The data obtained with the sf-BD-rHPLC method indicate that $\mathbf{1}$ is more stable

Table 2

Epimerization of $\left(3^{*}, 6 R\right)-\mathbf{1}$ at different temperatures by DCXplorer

\begin{tabular}{|c|c|c|c|c|}
\hline Temperature $\left({ }^{\circ} \mathrm{C}\right)$ & $k_{\mathrm{A}-\mathrm{to}-\mathrm{B}}\left(\mathrm{s}^{-1}\right)$ & $k_{\mathrm{B}-\mathrm{to}-\mathrm{A}}\left(\mathrm{s}^{-1}\right)$ & $k_{\mathrm{A}-\mathrm{to}-\mathrm{eq}}\left(\mathrm{s}^{-1}\right)$ & $\Delta G_{\mathrm{A}-\mathrm{to}-\mathrm{eq}}^{\#}(\mathrm{~kJ} / \mathrm{mol})$ \\
\hline 5 & $0.17 \pm 0.10 \times 10^{-4}$ & $0.06 \pm 0.06 \times 10^{-4}$ & $0.23 \pm 0.16 \times 10^{-4}$ & $91.06 \pm 1.22$ \\
\hline 25 & $1.11 \pm 0.02 \times 10^{-4}$ & $0.76 \pm 0.01 \times 10^{-4}$ & $1.87 \pm 0.02 \times 10^{-4}$ & $93.86 \pm 0.03$ \\
\hline 37 & $1.28 \pm 0.29 \times 10^{-4}$ & $0.71 \pm 0.11 \times 10^{-4}$ & $1.99 \pm 0.41 \times 10^{-4}$ & $96.41 \pm 0.47$ \\
\hline
\end{tabular}

Column: Chiralcel OD-R; Temperatures: 5,25 and $37^{\circ} \mathrm{C}$. Eluents: water/acetonitrile 50:50 (v/v). Flow rate: $0.5 \mathrm{~mL} / \mathrm{min}$. 
Table 3

Epimerization of $\left(3^{*}, 6 R\right)-\mathbf{1}$ by sf-BD-rHPLC on a C8 column

\begin{tabular}{|c|c|c|c|c|c|c|}
\hline $\mathrm{pH}$ & $k_{\text {A-to-eq }}\left(\mathrm{s}^{-1}\right)$ & $k_{\text {B-to-eq }}\left(\mathrm{s}^{-1}\right)$ & $k_{\mathrm{A}-\text { to-B }}\left(\mathrm{s}^{-1}\right)$ & $k_{\mathrm{B}-\text { to-A }}\left(\mathrm{s}^{-1}\right)$ & $\Delta G_{\mathrm{A}-\text { to-eq }}^{\#}(\mathrm{~kJ} / \mathrm{mol})$ & $\Delta G_{\mathrm{B}-\text { to-eq }}^{\#}(\mathrm{~kJ} / \mathrm{mol})$ \\
\hline 2.2 & $6.68 \pm 0.48 \times 10^{-4 a}$ & $6.52 \pm 0.79 \times 10^{-4 a}$ & $4.61 \pm 0.22 \times 10^{-4}$ & $2.26 \pm 0.03 \times 10^{-4}$ & $93.28 \pm 0.18^{\mathrm{b}}$ & $93.35 \pm 0.30^{\mathrm{b}}$ \\
\hline 7.0 & $5.90 \pm 0.56 \times 10^{-4 a}$ & $7.77 \pm 0.32 \times 10^{-4 a}$ & $4.49 \pm 0.61 \times 10^{-4}$ & $2.34 \pm 0.32 \times 10^{-4}$ & $93.60 \pm 0.23^{b}$ & $92.89 \pm 0.10^{\mathrm{b}}$ \\
\hline
\end{tabular}

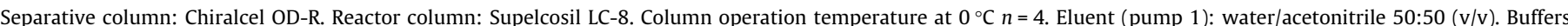

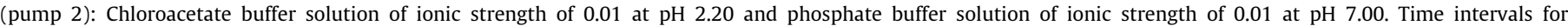
enantiomerization at $37.5^{\circ} \mathrm{C}=5^{\prime}, 10^{\prime}, 15^{\prime}, 20^{\prime}, 30^{\prime}$.

a Rate constants on a C8 column.

b Free energy barriers on a C8 column.

Table 4

Epimerization of $\left(3^{*}, 6 R\right)-1$ by sf-BD-rHPLC on an IAM stationary phase column

\begin{tabular}{|c|c|c|c|c|c|c|}
\hline $\mathrm{pH}$ & $k_{\mathrm{A}-\mathrm{to}-\mathrm{eq}}\left(\mathrm{s}^{-1}\right)$ & $k_{\text {B-to-eq }}\left(\mathrm{s}^{-1}\right)$ & $k_{\mathrm{A}-\text { to-B }}\left(\mathrm{s}^{-1}\right)$ & $k_{\text {B-to-A }}\left(\mathrm{s}^{-1}\right)$ & $\Delta G_{\mathrm{A}-\text { to-eq }}^{\#}(\mathrm{~kJ} / \mathrm{mol})$ & $\Delta G_{\mathrm{B}-\mathrm{to}-\mathrm{eq}}^{\#}(\mathrm{~kJ} / \mathrm{mol})$ \\
\hline 2.2 & $10.70 \pm 0.03 \times 10^{-4 a}$ & $9.63 \pm 0.07 \times 10^{-4 a}$ & $6.68 \pm 0.35 \times 10^{-4}$ & $3.48 \pm 0.18 \times 10^{-4}$ & $92.07 \pm 0.08^{b}$ & $92.34 \pm 0.02^{b}$ \\
\hline 7.0 & $7.20 \pm 0.55 \times 10^{-4 a}$ & $8.93 \pm 0.48 \times 10^{-4 a}$ & $5.30 \pm 0.57 \times 10^{-4}$ & $2.75 \pm 0.29 \times 10^{-4}$ & $93.09 \pm 0.19^{\mathrm{b}}$ & $92.53 \pm 0.14^{b}$ \\
\hline
\end{tabular}

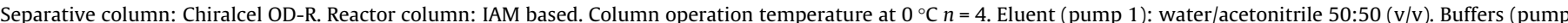

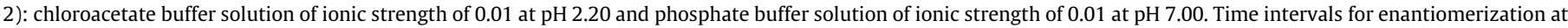
$37.5^{\circ} \mathrm{C}=5^{\prime}, 10^{\prime}, 15^{\prime}, 20^{\prime}, 30^{\prime}$.

a Rate constants on an IAM column.

b Free energy barriers on an IAM column.

to hydrolysis than IDRA21 under acidic conditions. Therefore, it can be hypothesized that 1 would not undergo hydrolysis to the corresponding benzensulfonamide when orally administered.

In vivo pharmacokinetic experiments in rats are in development in order to confirm the chemical stability of $\mathbf{1}$ towards acidic conditions like those of stomach.

\subsection{Biological activity}

Data obtained by the sf-BD-rHPLC method clearly indicated that single stereoisomers of $\mathbf{1}$ in saline solution undergo fast epimerization. Hence, testing single stereoisomers of $\mathbf{1}$ lacks significance, since biological tests are performed in saline solution. Therefore, biological activity was evaluated on epimeric mixtures $\left(3^{*}, 6 R\right)-1$ and $\left(3^{*}, 6 S\right)-\mathbf{1}$.

By using the patch clamp technique in whole cell configuration, Kainate (KA)-evoked currents were recorded from cortical neurons grown in primary cultures. KA evoked currents, mediated mainly by AMPAr, were potentiated by the co-application of epimeric mixtures $\left(3^{*}, 6 R\right)-\mathbf{1}$ or $\left(3^{*}, 6 S\right)-\mathbf{1}$.

$\left(3^{*}, 6 R\right)-\mathbf{1}$ and $\left(3^{*}, 6 S\right)-\mathbf{1}$, at a concentration of $100 \mu \mathrm{M}$, increased KA currents by $112.3 \pm 17.2 \%($ mean \pm SE) $(n=4)$ and $249.7 \pm 50.3 \%$ (mean $\pm \operatorname{SE})(n=4)$, respectively. The difference in biological activity between the two epimeric mixtures was statistically significant ( $t$-test, $p<0.05$ ).

These data indicate that the epimeric mixture $\left(3^{*}, 6 S\right)-\mathbf{1}$ is much more active in potentiating KA-evoked currents than the epimeric mixture $\left(3^{*}, 6 R\right)-1$. These experimental results are in accordance with docking results that indicate that $(3 S, 6 S)-\mathbf{1}$ is the most active of all four stereoisomers.

\section{Conclusion}

The stereoselectivity of compound $\mathbf{1}$ as an AMPAr positive allosteric modulator was investigated. Molecular docking simulations were used to investigate possible binding poses of the four stereoisomers of $\mathbf{1}$. These simulations confirmed that stereoisomers of $\mathbf{1}$ can display different interactions with the allosteric ligand binding site of AMPAr and thus have different levels of activity. Subsequently, in order to obtain single stereoisomers of $\mathbf{1}$, a synthetic and a chromatographic strategy was developed. Investigation of the stability of stereoisomers of $\mathbf{1}$ suggested that the C3 atom is a labile chiral center in aqueous solvents. Moreover, biological in vitro assays were conducted on both epimeric mixtures $\left(3^{*}, 6 S\right)-\mathbf{1},\left(3^{*}, 6 R\right)-\mathbf{1}$ and the results suggest that $\left(3^{*}, 6 S\right)-\mathbf{1}$ is significantly more active than $\left(3^{*}, 6 R\right)-\mathbf{1}$ as positive modulator of the AMPA receptor. These biological data are in accordance with in silico results.

\section{Experimental}

\subsection{Instrumentation}

The chromatographic apparatus was a Shimadzu LC-10AD Pump (Shimadzu Italia, Milan), a Merck Hitachi L-6200A Pump (Merck KGaA, Darmstadt, Germany), and a Rheodyne 7725 manual injector equipped with a $20 \mu \mathrm{L}$ sample loop (Jasco Europe, Italy, Milan). A Merck Hitachi L-7400UV (Merck KGaA, Darmstadt, Germany) was used as detector. Chromatograms were recorded with a Jasco J-700 program (Jasco Europe, Italy, Milan). Two Rheodyne 7000 valves were used to switch the mobile phase flow (Jasco Europe, Italy, Milan). Column temperature regulation was obtained with a Jasco CO-2067 column oven (Jasco Europe, Italy, Milan).

The columns used were a Chiralcel OD-R [cellulose tris (3,5-dimethylphenylcarbamate); $250 \times 4.6 \mathrm{~mm}$ I.D.; $10 \mu \mathrm{m}$ ], a Chiralcel OD [cellulose tris (3,5-dimethylphenylcarbamate); $250 \times 10 \mathrm{~mm}$ I.D.; $10 \mu \mathrm{m}$ ], a Chiralcel OJ-RH [cellulose tris (4methylbenzoate); $150 \times 4.6 \mathrm{~mm}$ I.D.; $5 \mu \mathrm{m}$ ], and a Chiralcel OB-H [cellulose tribenzoate; $250 \times 4.6 \mathrm{~mm}$ I:D.; $5 \mu \mathrm{m}$ ] purchased from Chiral Technologies Europe, Illkirch, France. Also used were a Supelcosil LC-8 $(250 \mathrm{~mm} \times 4.6 \mathrm{~mm}$ ID; $5 \mu \mathrm{m})$ purchased from Supelco Italy, Milan, and a Lichrospher Si60 $(250 \times 10 \mathrm{~mm}$ I.D.; $10 \mu \mathrm{m})$, purchased from Merck, German. Optical rotations $(\alpha)$ were measured with a P-2000 Digital Polarimeter (cell-length $100 \mathrm{~mm}$, volume $1 \mathrm{~mL}$ ) from Jasco Europe, Italy, Milan.

Melting points were determined with an Electrothermal Apparatus, and they are uncorrected.

IR spectra were recorded on a PerkinElmer Model 1600 FT-IR spectrometer. ${ }^{1} \mathrm{H}$ NMR spectra were recorded with a Brucker DPX 200 spectrometer with DMSO- $d_{6}$ as solvent and tetramethylsilane (TMS) as an external standard. Chemical shifts $(\delta)$ are in 
part per million and coupling constants $(J)$ are in hertz. Multiplicities are abbreviated as follows: s, singlet; d, doublet; dd, double doublet; dt, double triplet; $t$, triplet; $\mathrm{m}$, multiplet. The electrospray ionization (HR-ESI-MS) experiments were carried out on a hybrid QqTOF mass spectrometer (PE SCIEX-QSTAR) equipped with an ion spray ionization source. MS (+) spectra were acquired by direct infusion $(5 \mathrm{~mL} / \mathrm{min})$ of a solution containing the appropriate sample $(10 \mathrm{pmol} / \mathrm{mL})$, dissolved in a solution of $50: 50$ methanol/water containing $0.1 \%$ acetic acid at the optimum ion voltage of $4800 \mathrm{~V}$.

LC-MS experiments were carried out on an Agilent 1200 series LC and interfaced to an Agilent 6410 triple-quadrupole mass spectrometer equipped with an electrospray ionization source. All data were acquired and analyzed using Agilent MassHunter Quantitative Analyses version B.01.04 analyst data processing software.

All $\mathrm{pH}$ measurements were made using an Orion Research EA940 $\mathrm{pH}$-meter.

HPLC-grade acetonitrile, $n$-hexane and 2-propanol were obtained from Sigma-Aldrich (Milan, Italy).

\subsection{Docking studies}

The GluA2-S1S2J crystal structure in complex with IDRA21 was retrieved from the Protein Data Bank (PDB code: 3IL1) and imported into MVD. All water molecules and co-factors were deleted. All stereoisomers of compound $\mathbf{1}$ were built in Spartan and energies were minimized using theHartree-Fock ab initio method with the $6-31 \mathrm{G}^{*}$ basis set.

The four isomers of $\mathbf{1}$ were then exported as mol2 files and docked in GluA2 using MVD. We used the template docking available in MVD and evaluated MolDock score, Rerank score, and protein-ligand interaction score from MolDock and MolDock [GRID] options. IDRA21 was selected as a reference compound for the template. Default settings included a grid resolution of $0.30 \AA$, the MolDock optimizer as a search algorithm, the number of runs set to 10 , a population size of 50 , a maximum iteration of 2000 , a scaling factor of 0.50 , and a crossover rate of 0.90 . The maximum number of poses generated was increased to 10 from a default value of 5 .

\subsection{Synthesis}

4.3.1. $(3 R, 6 R),(3 S, 6 S),(3 R, 6 S),(3 S, 6 R)-8-C h l o r o-2,3,5,6$-tetrahydro -3,6-dimethyl-pyrrolo[1,2,3-de]-1,2,4-benzothiadiazine,1,1dioxide (1)

Compound 1 was synthesized as previously described by Philips et al. $^{15}$

Yield $27 \%$ (three steps), mp $185-187^{\circ} \mathrm{C},{ }^{1} \mathrm{H}$ NMR $(200 \mathrm{MHz}$, $\left.\mathrm{CDCl}_{3}\right) \delta=1.36(\mathrm{~d}, J=6.8 \mathrm{~Hz}, 3 \mathrm{H}), 1.52(\mathrm{~d}, J=6.1 \mathrm{~Hz}, 3 \mathrm{H}), 2.80$ (dd, $J=11.3,8.3 \mathrm{~Hz}, 1 \mathrm{H}), 3.40-3.47(\mathrm{~m}, 1 \mathrm{H}), 3.74(\mathrm{t}, J=8.3 \mathrm{~Hz}$, $1 \mathrm{H}), 4.56(\mathrm{~d}, J=12.6 \mathrm{~Hz}, 1 \mathrm{H}), 4.68(\mathrm{dq}, J=12.5,6.1 \mathrm{~Hz}, 1 \mathrm{H}), 7.10-$ $7.22(\mathrm{~m}, 1 \mathrm{H}), 7.30-7.47(\mathrm{~m}, 1 \mathrm{H})$.

HRMS-ESI: calcd for $\mathrm{C}_{11} \mathrm{H}_{14} \mathrm{ClN}_{2} \mathrm{O}_{2} \mathrm{~S}[\mathrm{M}+\mathrm{H}]^{+}$273.0459; found: 273.0456 .

\subsection{2. $\left(3^{*}, 6 R\right)-1$ and $\left(3^{*}, 6 S\right)-1$}

4.3.2.1. 2,3-Dihydro-3-methyl-1H-indole (3). The compound was synthesized as previously described by Gotor-Fernandez et al. starting from 3-methylindole (2). ${ }^{33}$

Yield 90\%, ${ }^{1} \mathrm{H}$ NMR $\left(200 \mathrm{MHz}, \mathrm{CDCl}_{3}\right) \delta=1.35(\mathrm{~d}, J=6.7 \mathrm{~Hz}, 3 \mathrm{H})$, $3.13(\mathrm{t}, J=8.5 \mathrm{~Hz}, 1 \mathrm{H}), 3.20(\mathrm{~s}$, broad, $1 \mathrm{H}), 3.38(\mathrm{~m}, 1 \mathrm{H}), 3.72(\mathrm{t}$, $J=8.5 \mathrm{~Hz}, 1 \mathrm{H}), 6.68(\mathrm{~d}, J=7.7 \mathrm{~Hz}, 1 \mathrm{H}), 6.77(\mathrm{dt}, J=7.4 \mathrm{~Hz}, 1.0 \mathrm{~Hz}$, $1 \mathrm{H}) ; 7.03$ (dt, $J=7.7 \mathrm{~Hz}, 1 \mathrm{~Hz}, 1 \mathrm{H}), 7.10$ (d, $J=7.4 \mathrm{~Hz}, 1 \mathrm{H})$.

HRMS-ESI: calcd for $\mathrm{C}_{9} \mathrm{H}_{12} \mathrm{~N}[\mathrm{M}+\mathrm{H}]^{+} 134.1977$; found: 134.1979 .
4.3.2.2. 2,3-Dihydro-3-methyl-1H-indole-1-carboxylic acid 1,1dimethyl ethyl ester (4). Compound 4 was synthesized as previously described by Carrozzo et al. ${ }^{26}$

Yield $80 \%,{ }^{1} \mathrm{H}$ NMR $\left(200 \mathrm{MHz}, \mathrm{CDCl}_{3}\right) \delta=1.33(\mathrm{~d}, J=6.7 \mathrm{~Hz}, 3 \mathrm{H})$, 1.50-1.62 (s, broad, 9H), $3.37(\mathrm{~m}, 1 \mathrm{H}), 3.50(\mathrm{~s}$, broad, $1 \mathrm{H}), 4.14(\mathrm{t}$, broad, $J=10.1 \mathrm{~Hz}, 1 \mathrm{H}), 6.68(\mathrm{~d}, J=7.7 \mathrm{~Hz}, 1 \mathrm{H}), 6.96(\mathrm{dt}, J=7.4 \mathrm{~Hz}$, $0.9 \mathrm{~Hz}, 1 \mathrm{H}) ; 7.13$ (d, $J=7.4 \mathrm{~Hz}, 1 \mathrm{H}), 7.46-7.83$ (s, broad, $1 \mathrm{H}$ ).

HRMS-ESI: calcd for $\mathrm{C}_{14} \mathrm{H}_{20} \mathrm{NO}_{2}[\mathrm{M}+\mathrm{H}]^{+}$234.3135; found: 234.3137.

4.3.2.3. Semipreparative enantioseparation of 2,3-dihydro-3methyl-1H-indole-1-carboxylic acid 1,1-dimethyl ethyl ester (4). Pure $(+)(S)$ and $(-)(R)$ enantiomers of 2,3-dihydro-3methyl-1H-indole-1-carboxylic acid 1,1-dimethyl ethyl ester were obtained by semipreparative HPLC on a Chiralcel OD semipreparative column with fraction collection of the respective peaks. The mobile phase consisted of $n$-hexane and 2-propanol 98:2 (v/v). The compound was dissolved in $n$-hexane at a final concentration of $400 \mathrm{mg} / \mathrm{mL}$. The injection volume was $500 \mu \mathrm{L}$. The detector was set at $254 \mathrm{~nm}$. The collected fractions corresponding to the enantiomers were analyzed by injection on the same column and under the same chromatographic conditions.

4.3.2.4. (R)-2,3-Dihydro-3-methyl-1H-indol-7-sulfonamide $((R)$ $5)$ and $(S)-2,3-d i h y d r o-3-m e t h y l-1 H$-indol-7-sulfonamide $((S)$ 5). The compounds were synthesized following the procedure described by Philips et al. ${ }^{15}$

Yield $42 \%$, mp $123-125{ }^{\circ} \mathrm{C},{ }^{1} \mathrm{H}$ NMR $\left(200 \mathrm{MHz}, \mathrm{CDCl}_{3}\right) \delta=1.34$ $(\mathrm{d}, J=6.7 \mathrm{~Hz}, 3 \mathrm{H}), 3.25(\mathrm{t}, J=8.2 \mathrm{~Hz}, 1 \mathrm{H}), 3.42(\mathrm{~m}, 1 \mathrm{H}), 3.84(\mathrm{t}$, $J=8.7 \mathrm{~Hz}, 1 \mathrm{H}), 4.90(\mathrm{~s}$, broad, $2 \mathrm{H}), 5.26(\mathrm{~s}$, broad, $1 \mathrm{H}), 6.71(\mathrm{t}$, $J=7.3 \mathrm{~Hz}, 1 \mathrm{H}), 7.19(\mathrm{dt}, J=7.1 \mathrm{~Hz}, 1.1 \mathrm{~Hz}, 1 \mathrm{H}), 7.44(\mathrm{dt}, J=8.0 \mathrm{~Hz}$, $0.9 \mathrm{~Hz}, 1 \mathrm{H})$.

HRMS-ESI: calcd for $\mathrm{C}_{9} \mathrm{H}_{13} \mathrm{~N}_{2} \mathrm{O}_{2} \mathrm{~S}[\mathrm{M}+\mathrm{H}]^{+}$213.2762; found: 213.2761.

4.3.2.5. (3*,6R)-6 and $\left(3^{*}, 6 S\right)-6$. The $\left(3^{*}, 6 R\right)-6$ and $\left(3^{*}, 6 S\right)-6$ were synthesized as previously described by Carrozzo et al. ${ }^{26}$

Yield 98\%, mp $=170-173{ }^{\circ} \mathrm{C},{ }^{1} \mathrm{H}$ NMR $(200 \mathrm{MHz}$, DMSO $) \delta=1.2$ (d, $J=6.9 \mathrm{~Hz}, 1 \mathrm{H}), 1.30$ (d, $J=6.7 \mathrm{~Hz}, 2 \mathrm{H}), 1.36-1.46(\mathrm{~m}, 3 \mathrm{H}), 2.82$ (dd, $J=11.1 \mathrm{~Hz}, 8.4 \mathrm{~Hz}, 0.67 \mathrm{H}), 3.22$ (dd, $J=8.0 \mathrm{~Hz}, 2.5 \mathrm{~Hz}, 0.33$ $\mathrm{H}), \quad 3.30-3.40(\mathrm{~m}, 1 \mathrm{H}), 3.48(\mathrm{t}, J=8.7 \mathrm{~Hz}, 0.33 \mathrm{H}), 3.72(\mathrm{t}$, $J=8.3 \mathrm{~Hz}, 0.67 \mathrm{H}$ ), 4.56 (apparent sextet, $J=6.1 \mathrm{~Hz}, 0.67 \mathrm{H}$ ), 4.66 (apparent sextet, $J=6.1 \mathrm{~Hz}, 0.33 \mathrm{H}), 6.71(\mathrm{t}, J=7.2 \mathrm{~Hz}, 0.33 \mathrm{H}$ ), $6.77(\mathrm{t}, J=7.2 \mathrm{~Hz}, 0.67 \mathrm{H}), 7.18-7.30(\mathrm{~m}, 2 \mathrm{H}), 7.82(\mathrm{~d}, J=11.4 \mathrm{~Hz}$, $0.33 \mathrm{H}), 7.89(\mathrm{~d}, J=11.4 \mathrm{~Hz}, 0.67 \mathrm{H})$.

HRMS-ESI: calcd for $\mathrm{C}_{11} \mathrm{H}_{15} \mathrm{~N}_{2} \mathrm{O}_{2} \mathrm{~S}[\mathrm{M}+\mathrm{H}]^{+} 239.3134$; found: 239.3136 .

4.3.2.6. $\left(3^{*}, 6 R\right)-1$ and $\left(3^{*}, 6 S\right)-1$. To a solution of $\left(3^{*}, 6 R\right)-6$ or $\left(3^{*}, 6 S\right)-6(1.0 \mathrm{mmol})$ in acetonitrile $(20 \mathrm{~mL})$ was added $N$-chlorosuccinimide $(1.2 \mathrm{mmol})$. The reaction mixture was heated under reflux conditions until no starting material was detected by TLC. Subsequently water was added, and the resulting solution was extracted with ethyl acetate (EtOAc). The combined organic layer was dried over anhydrous $\mathrm{Na}_{2} \mathrm{SO}_{4}$ and the solvent removed under vacuum. The solid residue was purified by column chromatography on silica gel (elution solvent/ethyl acetate/petroleum ether (bp 40$\left.60{ }^{\circ} \mathrm{C}\right), 1: 1(\mathrm{v} / \mathrm{v})$.

Yield 94\%, mp $185-187{ }^{\circ} \mathrm{C},{ }^{1} \mathrm{H}$ NMR $\left(200 \mathrm{MHz}, \mathrm{CDCl}_{3}\right) \delta=1.36$ $(\mathrm{d}, J=6.8 \mathrm{~Hz}, 3 \mathrm{H}), 1.52(\mathrm{~d}, J=6.1 \mathrm{~Hz}, 3 \mathrm{H}), 2.80$ (dd, $J=11.3$, $8.3 \mathrm{~Hz}, 1 \mathrm{H}), 3.40-3.47(\mathrm{~m}, 1 \mathrm{H}), 3.74(\mathrm{t}, J=8.3 \mathrm{~Hz}, 1 \mathrm{H}), 4.56(\mathrm{~d}$, $J=12.6 \mathrm{~Hz}, 1 \mathrm{H}), 4.68(\mathrm{dq}, J=12.6,6.1 \mathrm{~Hz}, 1 \mathrm{H}), 7.1-7.22(\mathrm{~m}, 1 \mathrm{H})$, 7.3-7.47 (m, 1H).

HRMS-ESI: calcd for C11H14CIN2O2S [M+H]+ 273.0459; found: 273.0456 . 


\subsection{Chromatography}

\subsection{1. $\left(3^{*}, 6 r\right)-1$}

Separation of $\left(3^{*}, 6 R\right)-\mathbf{1}$ was carried out isocratically at different temperatures on a Chiralcel OD-R column. The mobile phase consisted of water/acetonitrile 50:50 (v/v).

The compound was dissolved in acetonitrile and subsequently diluted $1: 10(\mathrm{v} / \mathrm{v})$ with mobile phase to a final concentration of $100 \mu \mathrm{g} / \mathrm{mL}$. The injection volume was $20 \mu \mathrm{L}$. The detector was set at $254 \mathrm{~nm}$.

\subsection{2. $\left(3^{*}, 6 s\right)-1$}

Separation of $\left(3^{*}, 6 S\right)$-1 was carried out isocratically on a Chiralcel OD-R column. The mobile phase consisted of water/acetonitrile 50:50 (v/v). The compound was dissolved in acetonitrile and subsequently diluted $1: 10(\mathrm{v} / \mathrm{v})$ with mobile phase to a final concentration of $100 \mu \mathrm{g} / \mathrm{mL}$. The injection volume was $20 \mu \mathrm{L}$. The detector was set at $254 \mathrm{~nm}$.

\subsection{3. $(R, S)$-5-chloro-2,3-dihydro-3-methyl-1H-indol-7- sulfonamide (7)}

Separation of $(R, S)$-5-chloro-2,3-dihydro-3-methyl-1H-indol-7sulfonamide from 1 was carried out isocratically on a Chiralcel OD-R column. The mobile phase was water/acetonitrile 50:50 (v/ $\mathrm{v) \text {. }}$

The compound was dissolved in acetonitrile and subsequently diluted $1: 10(\mathrm{v} / \mathrm{v})$ with mobile phase to a final concentration of $100 \mu \mathrm{g} / \mathrm{mL}$. The injection volume was $20 \mu \mathrm{L}$. The detector was set at $254 \mathrm{~nm}$.

\subsubsection{Chromatographic parameters}

The separation factor $(\alpha)$ was calculated as $k_{2} / k_{1}$ and retention factors $\left(k_{1}\right.$ and $\left.k_{2}\right)$ as $k_{1}=\left(t_{1}-t_{0}\right) / t_{0}$ where $t_{1}$ and $t_{2}$ refer to the retention times of the first and second eluted enantiomers. The resolution factor $\left(R_{\mathrm{s}}\right)$ was calculated by the formula $R_{\mathrm{s}}=2\left(t_{2}-t_{1}\right) /$ $\left(w_{1}+w_{2}\right)$ where $w_{1}$ and $w_{2}$ are the peak widths at base for the first and second eluted enantiomers. The dead time of the columns $\left(t_{0}\right)$ was determined by injection of 1,3,5-tri-tert-butylbenzene.

\subsubsection{Dynamic HPLC}

Epimerization kinetic parameters of $\left(3^{*}, 6 \mathrm{R}\right)-\mathbf{1}$ were investigated by dynamic chromatography experiments (DHPLC) using DCXplorer software developed by Trapp. ${ }^{34}$ The program employs the unified equation of chromatography to directly evaluate elution profiles in a graphical user interface. ${ }^{34-43}$ The software calculates reaction rate constants by integration of the area of the interconverting peaks.

Separation of $\left(3^{*}, 6 R\right)-\mathbf{1}$ epimers was carried out isocratically at different temperatures $\left(5-37^{\circ} \mathrm{C}\right)$ on a Chiralcel OD-R column using water/acetonitrile 50:50 (v/v) as mobile phase.

Since chromatograms corresponding to separation of epimeric mixture $\left(3^{*}, 6 R\right)-1$ obtained by UV-detector showed an interfering peak on the plateau region of interconverting epimers, DCXplorer cannot be applied to evaluate kinetic parameters of epimerization for $\left(3^{*}, 6 R\right)-1$. Therefore, instead of a UV detector a mass spectrometer was employed. This made it possible to extract chromatographic traces corresponding to the molecular ion of compound $\mathbf{1}$ where the interfering peak was not present. An Agilent 1200 LCsystem was connected to a triple quadrupole mass spectrometer (6410 Triple quadrupole) equipped with an electrospray ionization source (ESI). Data were processed by acquisition/processing Agilent MassHunter Quantitative software.

The mass spectrometer was operated in scan negative mode between $200-300 \mathrm{~m} / \mathrm{z}$, gas temperature $350^{\circ} \mathrm{C}$, gas flow $\left(\mathrm{N}_{2}\right)$ $10 \mathrm{~L} / \mathrm{min}$, nebulizer $35 \mathrm{psi}$, capillary $3500 \mathrm{nA}$.
Extracted ion chromatograms $\left(\mathrm{MH}^{-} 272 \mathrm{~m} / \mathrm{z}\right)$ row data in ASCIl were opened with the DCXplorer software and the elution profiles were evaluated by zooming into the area of the interconverting peaks. All chromatographic parameters were directly determined by an integration method and were used to calculate reaction rate constants. $^{34-43}$

\subsubsection{Stopped-flow bidimensional recycling HPLC (sf-BD- rHPLC)}

The sf-BD-rHPLC method has been previously described. ${ }^{26,27}$ The epimeric mixture $\left(3^{*}, 6 R\right)-\mathbf{1}$ was injected on the first column (Chiralcel OD-R) and the individual epimers were quantitatively separated at $0{ }^{\circ} \mathrm{C}$ (step 1 ). At the appropriate time one of the two epimers was trapped on the second column by switching valve 2 (step 2). Using pump 2 it was possible to fill the second column (Supelcosil LC-8 or IAM column) with a selected solvent at desired $\mathrm{pH}$ and temperature (step 3). The epimerization was effected by heating at $37.5^{\circ} \mathrm{C}$ while no mobile phase passed through column 2 ('stopped-flow') for a set period of time. Afterwards the C8 column was cooled back to the previous low temperature $\left(0^{\circ} \mathrm{C}\right)$ and valve 1 was switched. The original mobile phase was reinforced in column 2 by pump 2 to introduce the epimers onto the first column (Chiralcel OD-R) where they were quantitatively separated (step 4).

Three peaks appeared as expected: peak $1^{\circ}$ corresponding to untrapped epimer, peak $3^{\circ}$ corresponding to epimer trapped in step 2 while peak $2^{\circ}$ arising from interconverted epimer formed in step 3.

\subsubsection{Calculation of kinetic rate constants and free energy barriers of epimerization}

The kinetic rate constants were calculated by fitting the data to Eqs. (1)-(3):

$$
\begin{aligned}
& \operatorname{In} \frac{[\mathrm{A}]_{0}-[\mathrm{A}]_{\mathrm{eq}}}{[\mathrm{A}]_{\mathrm{t}}-[\mathrm{A}]_{\mathrm{eq}}}=\left(k_{\mathrm{A}-\mathrm{to}-\mathrm{B}}+K_{\mathrm{A}-\mathrm{to}-\mathrm{B}}\right)=k_{\mathrm{A}-\text { to-eq }} * \mathrm{t} \\
& K_{\text {eq }}=\frac{k_{\mathrm{A}-\text { to }-\mathrm{B}}}{k_{\mathrm{B}-\text { to }-\mathrm{A}}}=\frac{[\mathrm{B}]_{\mathrm{eq}}}{[\mathrm{A}]_{\mathrm{eq}}} \\
& k_{\mathrm{A}-\text { to-eq }}=k_{\mathrm{A}-\mathrm{to}-\mathrm{B}}\left(1+1 / K_{\mathrm{eq}}\right)=k_{\mathrm{B}-\text { to-A }}\left(1+K_{\mathrm{eq}}\right)
\end{aligned}
$$

where $k_{\mathrm{A} \text {-to-B }}$ and $k_{\mathrm{B} \text {-to-A }}$ are the rate constants of forward or backward epimerization $\left[\mathrm{s}^{-1}\right], k_{\mathrm{A}-\mathrm{t} \text {-eq }}$ is the rate constant of formation of equilibrium mixture $\left[\mathrm{s}^{-1}\right],[\mathrm{A}]_{0}$ concentration of decreasing stereoisomer $(A)$ at time $0,[A]_{t}$ concentration of decreasing stereoisomer $(\mathrm{A})$ at time $t,[\mathrm{~A}]_{\mathrm{eq}}$ concentration of decreasing stereoisomer $(\mathrm{A})$ at equilibrium, $[B]_{\text {eq }}$ concentration of increasing stereoisomer (B) at equilibrium and $t$ the epimerization time (s).

From the kinetic rate constants, the corresponding activation energies of epimerization (rotational energy barriers) $\Delta G^{\#}(T)$ have been calculated by the Eyring Eq. 4:

$\Delta G^{\#}(T)=-R T \ln \left(\frac{\mathrm{kh}}{\kappa k_{B} T}\right)$

where $k$ is kinetic rate constant, $k_{\mathrm{B}}$ the Boltzmann constant $\left(k_{\mathrm{B}}=1.380662 \times 10^{-23} \mathrm{~J} \mathrm{~K}^{-1}\right), h$ Planck's constant $(h=6.626176$ $\left.\times 10^{-34} \mathrm{~J} \mathrm{~s}\right), R$ the universal gas constant $\left(R=8.31441 \mathrm{~J} \mathrm{~K} \mathrm{~mol}^{-1}\right), \kappa$ the transmission coefficient ( $\kappa=0.5$ for the reversible microscopic interconversion) and $T$ the temperature (K).

\subsection{Biological tests}

\subsubsection{Primary culture}

Primary cultures of cortical neurons were prepared from newborn Sprague-Dawley rats as reported in the literature. ${ }^{51}$ Briefly, cells from the cortex were dispersed with trypsin $(0.24 \mathrm{mg} / \mathrm{mL}$; 
Sigma Aldrich, Milan, Italy) and plated at a density of $0.8 \times 10^{6}$ cells $/ \mathrm{mL}$ on $35 \mathrm{~mm}$ Falcon dishes coated with poly-t-lysine $(10 \mu \mathrm{g} / \mathrm{mL}$, Sigma Aldrich). Cells were plated in basal Eagle's Medium (BME; Celbio, Milan, Italy), supplemented with 10\% fetal bovine serum (Celbio), $2 \mathrm{mM}$ glutamine, $25 \mathrm{mM} \mathrm{KCl}$ and $100 \mu \mathrm{g} / \mathrm{mL}$ gentamycin (Sigma Aldrich) and maintained at $37{ }^{\circ} \mathrm{C}$ in $5 \% \mathrm{CO}_{2}$. After $24 \mathrm{~h}$ in vitro, the medium was replaced with 1:1 mixture of BME and Neurobasal medium (Celbio, Milan) containing 2\% B27 supplement, $1 \%$ antibiotic, and $0.25 \%$ glutamine (Invitrogen). At 5 days in vitro (DIV5), cytosine arabinofuranoside (Ara-C) was added at a final concentration of $1 \mu \mathrm{M}$.

\subsubsection{Electrophysiological recordings}

Recordings were performed at room temperature, under voltage-clamp in the whole-cell configuration of the patch-clamp technique on cells at DIV7-10. ${ }^{52}$ Electrodes pulled from borosilicate glass (Hidelberg, FRG) on a vertical puller (PB-7, Narishige) and had a resistance of-MOhm. Currents were amplified with an Axopatch 1D amplifier (Axon Instruments, Foster). The recording chamber was continuously perfused at $5 \mathrm{~mL} / \mathrm{min}$ with an artificial extracellular solution composed of (mM): $145 \mathrm{NaCl}, 5 \mathrm{KCl}, 1 \mathrm{CaCl}_{2}$, 5 Hepes, 5 Glucose, 20 Sucrose, pH 7.4 with NaOH. Electrode intracellular solution contained $(\mathrm{mM}): 140 \mathrm{KCl}, 3 \mathrm{MgCl}_{2}, 5 \mathrm{EGTA}, 5$ Hepes, 2 ATP-Na, pH 7.3 with $\mathrm{KOH}$. Drugs were applied directly by gravity through a Y-tube perfusion system. ${ }^{53}$

\section{References and notes}

1. Krogsgaard-Larsen, P.; Ebert, B.; Lund, T. M.; Brauner-Osborne, H.; Slk, F. A.; Johansen, T. N.; Brehm, L.; Madsen, U. Eur. J. Med. Chem. 1996, 31, 515.

2. Excitatory Amino Acid Receptors, Design of Agonists and Antagonists; KrogsgaardLarsen, P., Hansen, J. J., Eds.; Ellis Horwood: Chichester, 1992.

3. The NMDA Receptor; Collingridge, G. L., Watkins, J. C., Eds.; Oxford University Press: Oxford, 1994.

4. Kew, J. N. C.; Kemp, J. A. Psychopharmacology 2005, 179, 4.

5. Mayer, M. L.; Armstrong, N. Annu. Rev. Physiol. 2004, 66, 161.

6. Dicou, E.; Rangon, C. M.; Guimiot, F.; Spedding, M.; Gressens, P. Brain Res. 2003 $970,221$.

7. Morrow, J. A.; Maclean, J. K. F.; Jamieson, C. Curr. Opin. Drug Disc. Dev. 2006, 9, 571.

8. Marenco, S.; Weinberger, D. R. CNS Drugs 2006, 20, 173.

9. O, M. J.; Dix, S. IDrugs 2007, 10, 185.

10. O’Neill, M. J.; Witkin, J. M. Curr. Drug Targets 2007, 8, 603.

11. Ren, J.; Poon, B. Y.; Tang, Y.; Funk, G. D.; Greer, J. J. Am. J. Respir. Crit. Care Med. 2006, 174,1384

12. Zarate, J.; Manji, H. K. Exp. Neurol. 2008, 211, 7

13. Grove, S. J. A.; Jamieson, C.; Maclean, J. C. F.; Morrow, J. A.; Rankovic, Z. J. Med Chem. 2010, 53, 7271.

14. Ward, S. E.; Bax, B. D.; Harries, W. Br. J. Pharmacol. 2010, 160, 181.

15. Philips, D.; Sonnenberg, J.; Arai, A. C.; Vaswani, R.; Krutzik, P. O.; Kleisli, T.; Kessler, M.; Granger, R.; Lynch, G.; Chamberline, A. R. Bioorg. Med. Chem. 2002 $10,1229$.

16. Braghiroli, D.; Puia, G.; Cannazza, G.; Tait, A.; Parenti, C.; Losi, G.; Baraldi, M. J. Med. Chem. 2002, 45, 2355.
17. Pirotte, B.; Podona, T.; Diouf, O.; de Tullio, P.; Lebrun, P.; Dupont, L.; Somers, F.; Delarge, J.; Morain, P.; Lestage, P.; Lepagnol, J.; Spedding, M. J. Med. Chem. 1998 $41,2946$.

18. Graindorge, E.; Francotte, P.; Boverie, S.; de Tullio, P.; Pirotte, B. Curr. Med. Chem. 2004, 4, 95.

19. Hashimoto, K.; Okamura, N.; Shimizu, E.; Iyo, M. Curr. Med. Chem. 2004, 4, 147.

20. Black, M. D. Psychopharmacology 2005, 179, 154.

21. Francotte, P.; de Tullio, P.; Goffin, E.; Dintilhac, G.; Graindgorge, E.; Fraikin, P.; Lestage, P.; Danober, L.; Thomas, J. Y.; Caignard, D. H.; Pirotte, B. J. Med. Chem. 2007, 50, 3153.

22. Cannazza, G.; Braghiroli, D.; Tait, A.; Baraldi, M.; Parenti, C.; Lindner, W. Chirality 2001, 13, 94.

23. Cannazza, G.; Carrozzo, M. M.; Braghiroli, D.; Parenti, C. J. Chromatogr. A 2008, 1212, 41.

24. Carrozzo, M. M.; Cannazza, G.; Battisti, U.; Braghiroli, D.; Parenti, C. Chirality 2010, 22, 389.

25. Cannazza, G.; Carrozzo, M. M.; Battisti, U.; Braghiroli, D.; Parenti, C.; Troisi, A.; Troisi, L. Chirality 2010, 22, 789.

26. Carrozzo, M. M.; Cannazza, G.; Battisti, U. M.; Braghiroli, D.; Troisi, L.; Parenti, C. J. Chromatogr. A 2010, 1217, 8136.

27. Cannazza, G.; Battisti, U. M.; Carrozzo, M. M.; Brasili, L.; Braghiroli, D.; Parenti, C. Chirality, 2010, in press.

28. Cannazza, G.; Carrozzo, M. M.; Braghiroli, D.; Parenti, C. J. Chromatogr. B 2008, $875,42$.

29. Harpsoe, K.; Varming, T.; Gouliiaev, A. H.; Peters, D.; Liljefors, T. J. Mol. Graphics Modell. 2007, 26, 213.

30. Desos, P.; Serkiz, B.; Morain, P.; Lepagnol, J.; Cordi, A. Bioorg. Med. Chem. Lett. 1996, 6, 3003.

31. Ptak, C. P.; Ahmed, A. H.; Oswald, R. E. Biochemistry 2009, 48, 8594.

32. Thomsen, R.; Christensen, M. H. J. Med. Chem. 2006, 49, 3315.

33. Gotor-Fernandez, V.; Fernandez-Torres, P.; Gotor, V. Tetrahedron asymmetry 2006, 17, 2558.

34. Trapp, O. DCXplorer is available from the author as executable programs, running under Microsoft Windows 2000, XP and Vista.

35. Trapp, O. Anal. Chem. 2006, 78, 89.

36. Trapp, O. Chirality 2006, $18,489$.

37. Trapp, O. Electrophoresis 2006, 27, 534.

38. Trapp, O. Electrophoresis 2007, 28, 691.

39. Trapp, O.; Schurig, V. J. Am. Chem. Soc. 2000, 122, 1424.

40. Trapp, O.; Weber, S. K.; Bauch, S.; Hofstadt, W. Angew. Chem., Int. Ed. 2007, 46, 7307.

41. Trapp, O. J. Chromatogr. A 2008, 11, 160

42. Trapp, O.; Schurig, V. Comput. Chem. 2001, 25, 187.

43. Trapp, O. J. Chromatogr. B 2008, 875, 42.

44. Ong, S.; Liu, H.; Qiu, X.; Bhat, G.; Pidgeon, C. Anal. Chem. 1995, 67, 755.

45. Ong, S.; Cai, S. J.; Barnal, C.; Rhee, D.; Qiu, X.; Pidgeon, C. Anal. Chem. 1994, 66, 782.

46. Pidgeon, C.; Venkataram, U. V. Anal. Biochem. 1989, 176, 36.

47. Taillardat-Bertschinger, A.; Carrupt, P. A.; Barbato, F.; Testa, B. J. J. Med. Chem 2003, 46, 655.

48. Taillardt-Bertschinger, A.; Barbato, F.; Quercia, M. T.; Carrupt, P. A.; Reist, M.; La Rotonda, M. I.; Testa, B. Helv. Chim. Acta 2002, 85, 519.

49. Barbato, F.; La Rotonda, M. I.; Quaglia, F. J. Pharm. Sciences 1996, 86, 225.

50. Cannazza, G.; Krzsyztof, J.; Parenti, C.; Braghiroli, D.; Carrozzo, M. M.; Puia, G.; Losi, G.; Baraldi, M.; Lindner, W.; Wainer, I. W. Bioorg. Med. Chem. Lett. 2009, 19, 1254.

51. Luo, J. H.; Fu, Z.; Losi, G.; Kim, B. G.; Prybylowski, K.; Vissel, B.; Vicini, S. Neuropharmacology 2002, 42, 306.

52. Hamill, O. P.; Marty, A.; Neher, E.; Sakmann, B.; Sigworth, F. J. Pflügers Arch. 1981, 391, 85.

53. Murase, K.; Ryu, P. D.; Randic, M. Neurosci. Lett. 1989, 103, 56. 